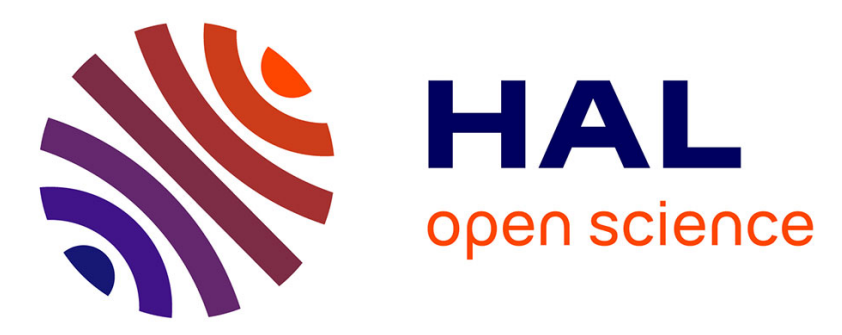

\title{
Tailoring bulk and surface grafting of poly(acrylic acid) in electron-irradiated PVDF
}

Marie-Claude Clochard, J Bègue, A Lafon, D Caldemaison, C Bittencourt, J.-J Pireaux, N Betz

\section{- To cite this version:}

Marie-Claude Clochard, J Bègue, A Lafon, D Caldemaison, C Bittencourt, et al.. Tailoring bulk and surface grafting of poly(acrylic acid) in electron-irradiated PVDF. Polymer, 2004, 45, pp.8683. 10.1016/j.polymer.2004.10.052 . hal-01129036

\section{HAL Id: hal-01129036 https://hal.science/hal-01129036}

Submitted on 12 Mar 2015

HAL is a multi-disciplinary open access archive for the deposit and dissemination of scientific research documents, whether they are published or not. The documents may come from teaching and research institutions in France or abroad, or from public or private research centers.
L'archive ouverte pluridisciplinaire HAL, est destinée au dépôt et à la diffusion de documents scientifiques de niveau recherche, publiés ou non, émanant des établissements d'enseignement et de recherche français ou étrangers, des laboratoires publics ou privés. 


\title{
Tailoring bulk and surface grafting of poly(acrylic acid) in electron- irradiated PVDF
}

M-Cl. Clochard ${ }^{1}$, J. Bègue ${ }^{1}$, A. Lafon ${ }^{1}$, D. Caldemaison², C. Bittencourt ${ }^{3}$, J-J. Pireaux ${ }^{3}$, N. Betz ${ }^{1^{*}}$

1. CEA-Saclay, DSM/DRECAM/LSI/LPI-Bat.466, F-91191 Gif-sur-Yvette Cédex, France

2. LMS, Ecole Polytechnique, Route de Saclay, F-91128 Palaiseau Cédex, France

3. LISE, FUNDP, 61 Rue de Bruxelles, B-5000 Namur, Belgique

\begin{abstract}
Endowing conventional hydrophobic poly(vinylidene fluoride) (PVDF) films with hydrophilic properties was conducted using electron beam irradiation. Grafting of acrylic acid (AA) in/onto pre-irradiated PVDF films was investigated. Reaction parameters, monomer concentration and inhibitor concentration were examined. Radiation grafted films (PVDF-g-PAA) were synthesized with various grafting yields ranging from $12 \mathrm{w} \%$ to $130 \mathrm{w} \%$ in presence of Mohr's salt ( $25 \mathrm{w} \%)$. Below $80 \mathrm{w} \%$ of monomer concentration, the degree of swelling was found to increase with the grafting yield. The PAA was arranged randomly in all PVDF matrix (grafting through). Above $80 \mathrm{w} \%$ of monomer concentration, the PAA was grafted only onto the surface of PVDF films leading to a highly dense layer of PAA. Grafting through or surface grafting processes were achieved by varying the water fraction in the initial monomer solution. Water molecule acts not only as a carrier for the monomer but also as a plasticizer expanding the film in the three dimensions. Evidences of grafting through and surface grafting were produced using FTIR in ATR mode, SEM coupled to X-ray detection and XPS. An accurate quantification of AA units was possible up to the micromole via a $\mathrm{Cu}^{2+}$-EDTA complex analyzed by UV-vis spectroscopy.
\end{abstract}

(Key Words: PVDF; radiation grafting; acrylic acid) 


\section{INTRODUCTION}

Because of its excellent mechanical and physico-chemical properties, poly(vinylidene fluoride) (PVDF) has found wide-spread industrial applications and research interest since the 1960s. In recent years, hydrophilic PVDF membranes used in microfiltration and ultrafiltration from chemical and physical modification have been widely studied [1,2] and applied for non-conventional field such as drug delivery [3,4]. Several approaches have been developed to endow the conventional hydrophobic membranes with hydrophilic properties. These approaches have included coating and grafting. In the latter approach, various techniques were used for acrylic acid (AA) grafting onto various hydrophobic polymers : pulsed plasma [5,6,7], corona discharge [8], ozone treatment [1], gamma radiation $[9,10,11,7]$, electron beam irradiation $[12,13] \ldots$ Ionizing radiation has the advantage of inducing the formation of stable alkyl and peroxy radicals in PVDF films $[14,15,16,17]$. These radicals are stabilized by the PVDF crystalline zones. Therefore, films can be stored for several years before use. This elegant technique permits to control various parameters such as the dose-rate and the absorbed dose which is proportional to the number of active radical sites inducing further grafting. Consequently, reproducible pre-irradiated PVDF films are obtained leading to proper and easy-going grafting results even after a long-term period.

Radiografting process of a monomer is obviously driven by polymerization parameters. The initiation step depends on nature and amount of electronic defaults induced by ionizing radiation. The number of excitation and ionization events increases with the absorbed dose as a consequence of the electronic interactions of the incident electrons with the polymer. The formed primary species reorganize to form stable radicals and other molecular defects (mainly unsaturated bonds and crosslinks). When the irradiated films are in contact with air after irradiation, radicals can react with oxygen leading to the formation of peroxy radicals (POO*) which can recombine and lead to the formation of peroxides (POOP), 
hydroperoxides $(\mathrm{POOH})$, acids, alcohols or ketones. As described by Chapiro [21,22] grafting reactions on peroxidized polymers usually proceeds via thermal decomposition of peroxides and hydroperoxydes which leads to alkoxy ( $\left.\mathrm{PO}{ }^{*}\right)$ radicals able to initiate radical addition polymerization of monomers. But it is known that peroxy radicals have considerable lifetime at room temperature and are extremely resistant to heat [23]. Additional studies lead to the conclusion that grafting was initiated from $\mathrm{P}$ radicals resulting from the deoxygenation of trapped peroxy radicals $[24,16,25,29]$.

Introducing hydrophilic groups on PVDF films surface is of biological great interest. Indeed, the covalent immobilization of proteins on the hydrophilic surface of polymeric support is generally considered as a promising approach to enhance blood or tissue compatibility of biomaterials [18]. In the present study, acrylic acid (AA) has been chosen as hydrophilic monomer. A first step to reach biomedical goal is to study PVDF-g-PAA films. Grafting parameters such as inhibitor effect, absorbed dose, kinetics and monomer concentration are then investigated. After few experiments, it has been found such of interest to observe so dramatic changes of mechanical films properties from one range to another depend to water content that we choose to investigate furthermore grafted films structures. No relative paper mentioned this type of grafted PVDF film behaviour. The structure of the resulting graft copolymers is studied using FTIR in transmission and ATR mode, SEM coupled to X-ray detection and XPS. Finally, AA units are quantified by UV-vis spectroscopy via toluidine blue and $\mathrm{Cu}^{2+}$-EDTA complexes. 


\section{EXPERIMENTAL SECTION}

\subsection{Materials and Reagents}

The following chemicals were purchased from Sigma-Aldrich and used as received: acrylic acid (AA) stabilized with 200 ppm hydroquinone, Mohr's salt $\left[\mathrm{FeH}_{8} \mathrm{~N}_{2} \mathrm{O}_{8} \mathrm{~S}_{2} \cdot 6 \mathrm{H}_{2} \mathrm{O}\right]$, potassium tert-butoxide $\mathrm{C}_{4} \mathrm{H}_{9} \mathrm{OK} 95 \%$, sulfuric acid $\mathrm{H}_{2} \mathrm{SO}_{4}$, copper II chloride, toluidine blue powder. From Merck, Titrisol® of $0.1 \mathrm{M} \mathrm{NaOH}$ and $0.1 \mathrm{M} \mathrm{HCl}$ were used for titration purpose. Hydrophobic PVDF films (PVDF $\alpha$ Atochem., $25 \mu \mathrm{m}$ thick) were Soxhlet-extracted in toluene and dried at $50{ }^{\circ} \mathrm{C}$ under vacuum. EPON® resin (Fluka) was prepared following Fluka's instructions with 2 polymerization temperature steps. Ion-exchange water was used throughout.

\subsection{Radiation grafting of PVDF with Acrylic Acid}

Post-irradiation grafting was accomplished by first irradiating the PVDF films at room temperature under a helium atmosphere using a $2.5 \mathrm{MeV}$ Van de Graaf accelerator. Films were irradiated at $150 \mathrm{kGy}$ (dose-rate: $500 \mathrm{kGy} / \mathrm{h}$ ). Immediately after irradiation, films were stored under nitrogen atmosphere at room temperature. Before grafting, films were cut $\left(\sim 20 * 20 \mathrm{~mm}^{2}\right)$, measured (surface area and thickness) weighted and characterized by FTIR spectroscopy. Then, the films were immersed at room temperature into a grafting solution containing AA. Under these conditions, more than $99 \%$ of acrylic acid monomer will be present in the non-ionized form. Mohr's salt was added to the grafting solution to avoid homopolymerization $(0.25 \mathrm{w} \%$ concentration for most experiments). These solutions were deaerated by bubbling nitrogen during $15 \mathrm{~min}$ in glass tubes. Tubes were hermetically closed and put into a thermostated silicon oil bath at $60{ }^{\circ} \mathrm{C}$ for 1 hour otherwise stipulated. Films were first washed in fresh water and then Sohxlet-extracted in boiled water overnight. Films 
were dried at $50{ }^{\circ} \mathrm{C}$ in vacuum to constant weight. The grafting yield $\mathrm{Y}$ was determined gravimetrically according to the following formula:

$$
Y(w t \%)=\frac{m_{f}-m_{i}}{m_{i}} .100
$$

where $m_{f}$ and $m_{i}$ are the weights of grafted and initial film, respectively.

\subsection{Infrared Spectroscopy Measurements}

FTIR spectra of the polymer films were carried out with a Nicolet Magna-IR ${ }^{\mathrm{TM}} 750$ spectrometer equipped with a DTGS detector. The sample compartment is continuously purged with by a nitrogen flux. In order to improve the quality of the spectra in transmission mode, measurements were recorded positioning the samples at the Brewster's angle to eliminate interference fringes. Background acquisition was performed before each sample acquisition. To analyze the first micrometers of the film, spectra were recorded in an Attenuated Total Reflection mode (ATR) using a diamond-crystal with single reflection. Both spectra were collected by cumulating 32 scans at a resolution of $2 \mathrm{~cm}^{-1}$.

\section{$2.4 U$-vis spectroscopy}

A UNICAM model UV 300 spectrophotometer was used to measure the maximum absorbance at $633 \mathrm{~nm}$ for toluidine blue solutions and $740 \mathrm{~nm}$ for $\mathrm{Cu}^{2+}$-EDTA complex. Toluidine blue protocol was described by Kang et al [19]. Quantification by cupric ions was developed in our laboratory. PVDF-g-PAA films were put in $20 \mathrm{ml}$ of $0.1 \mathrm{M} \mathrm{NaOH}$ solution during $30 \mathrm{~min}$. Films were then rapidly dried on filter paper and checked by FTIR to determine the complete carboxyl ionization. Films were transferred to $10 \mathrm{ml}$ of $0.1 \mathrm{M} \mathrm{CuCl}_{2}$ (or $\mathrm{CuSO}_{4}$ ) solutions and stirred for at least 1 hour. After a quick rinsing in deionized water, films were immersed in a 0.1 M EDTA solution for an additional hour. All the cupric ions were desorbed in a $\mathrm{Cu}^{2+}$-EDTA complex form analyzed by UV-vis spectroscopy. Assuming 
that $\mathrm{Cu}^{2+}$ ion reacts with two carboxylate groups, it is then easy to deduce the number of carboxyl groups present in a PVDF-g-PAA film. The best limit of this dosing method was found to be the micromole.

\subsection{Scanning Electron Microscopy}

Scanning electron microscopy (SEM) has been carried out with a Phillips apparatus equipped with $\mathrm{LaB}_{6}$ tip, and coupled with a PGT-Princeton Gamma Tech. X-ray detector and a PRISM Digital spectrometer (LMS, Ecole Polytechnique). The used technology is based on Energy Dispersive System (EDS). Samples were firstly immersed in a potassium tertbutoxyde solution $(8: 8 \mathrm{w} / \mathrm{w})$. A vivid violet colored the films. Then, films were embedded in EPON resin before being cut by a Leica microtome. The cut edge was coated with Au using a sputtering device and analyzed.

\section{$2.6 \quad X$-Ray Photelectron Spectroscopy (XPS)}

X-ray photoelectron spectra were recorded on a HP5950A spectrometer using a monochromatic Al Ka X-ray source $(1486.6 \mathrm{eV})$. The concentric hemispherical electron energy analyzer is equipped with a multichannel detector operating at a constant energy analyzer mode at electron take-off angle of $51.5^{\circ}$. The use of a flood gun permits to reduce charge effects. A pass energy of $50 \mathrm{eV}$ is used for both the survey and core level scans. The resolution was between $0.8-1 \mathrm{eV}$. Binding energies were determined by reference to the $\mathrm{C}_{1 \mathrm{~S}}$ component due to carbon bond only to carbon and hydrogen, set at $285 \mathrm{eV}$. Linear baseline for background subtraction and Gaussian functions were used for peak fitting. Atomic percentages were determined from peak areas by using Scofield factors $[20]\left(C_{1 S}=1, F_{1 S}=4.43\right.$, $\left.\mathrm{O}_{1 \mathrm{~S}}=2.93, \mathrm{~N}_{1 \mathrm{~S}}=1.8, \mathrm{Si}_{2 \mathrm{P}}=0.817\right)$. 


\section{RESULTS AND DISCUSSION}

\subsection{Initiation of grafting}

In Figure 1a,a' are shown the transmission spectra of a $150 \mathrm{kGy}$-the maximum absorbed dose used in the work- electron irradiated PVDF sample compared to that of a virgin sample. Indeed, as emphasized on the subtraction spectrum, irradiation and post-irradiation induced defects are observed. Nevertheless, these defects consist mainly in oxidation defects and dehydrofluorination. In the $\mathrm{OH} / \mathrm{CH}$ valence absorption region, superimposed on an interference fringe, a narrow band at $3650 \mathrm{~cm}^{-1}$ and three large bands at 3620, 3580 and 3540 $\mathrm{cm}^{-1}$ are observed and assigned as in $\mathrm{P}(\mathrm{VDF} / \mathrm{HFP})$. The hydroperoxide concentration value is $0.4 \mu$ mol. $\mathrm{kg}^{-1}$. Chain scission as followed by the $1754.6 \mathrm{~cm}^{-1}$ absorption band scarcely occurs. Therefore it can be concluded that little irradiation effects and oxidation occur at $150 \mathrm{kGy}$ in the PVDF samples. Hydroperoxides are formed that could give rise to grafted chains and homopolymer. In order to evaluate the thermal stability of hydroperoxides, annealing of 150 kGy electron irradiated films was performed at $60{ }^{\circ} \mathrm{C}$ during $24 \mathrm{~h}$ under $\mathrm{N}_{2}$ atmosphere. As all the other radiolysis and oxidation products[30], they are stable at the temperature used for grafting (Figure 1b, $b^{\prime}$ ). Only a small increase of the free end-chain alcohol occurs. This is presumably due to peroxy radical conversion induced by heating. As it was pointed out in introduction, mainly the stable alkyl and peroxy radicals are able to initiate the grafting reaction. In our case, hydroperoxides are formed in low quantity compared to radicals and are stable at the grafting temperature used. Peroxides even if formed in comparable yields than hydroperoxides are expected to have higher stability than hydroperoxides and therefore do not contribute to grafting. Consequently, it can be concluded that further PAA grafts would be mainly initiated from stable alkyl radicals located in PVDF crystalline zones. 


\subsection{Grafting parameters}

According to previous experiments, grafting experiments were performed at $60^{\circ} \mathrm{C}$ during $1 \mathrm{~h} \mathrm{[12].} \mathrm{At} \mathrm{this} \mathrm{temperature,} \mathrm{thermal} \mathrm{polymerization} \mathrm{of} \mathrm{acrylic} \mathrm{acid} \mathrm{occurs} \mathrm{leading} \mathrm{to}$ significative homopolymer presence in solution. Therefore addition of inhibitor to the monomer solution is needed to minimize this homopolymerization effect. At the same time, hindering of the grafting reaction cannot be excluded, the minor consequence being a lowering of the grafting yield. A well-known AA inhibitor, Mohr's salt, has been tested on a $75 \%$ monomer solution (Figure 2). At this concentration, films are highly grafted and grafting takes place in the bulk of the film which exhibits a 3D increase of its dimensions. We have deliberately chosen these conditions in order to appreciate at most the impact of inhibitor on grafting yield and homopolymerization effect. As expected, no homopolymerization occurs in solution. The grafting yield falls with increasing inhibitor concentration from $130 \%$ at 0.01 [Mohr's salt] w \% to $70 \%$ where it remains stable (Figure 2). Indeed, at the same time homopolymerization is stopped, the inhibitor speeds up the termination reaction thus yielding lower grafting yields. Inhibitor's contribution reaches a maximum at a concentration of 0.25 $\mathrm{w} \%$.

In order to determine optimal grafting conditions, grafting kinetics were performed at $60^{\circ} \mathrm{C}$. As shown in previous swelling experiments of AA in pristine PVDF, a high temperature favors monomer diffusion in films but also favors homopolymerization [12]. A temperature of $60{ }^{\circ} \mathrm{C}$ was a good compromise. Figure 3 displays experimental grafting kinetics obtained at two different doses, 30 and $100 \mathrm{kGy}$. Grafting yield sharply increases in the first hour. Beyond 1 hour, the grafting rate slows down leading to an asymptotic saturation of the grafting yield. Large standard deviations on grafting yields are observed after 4 hours especially on the $30 \mathrm{kGy}$ irradiated films: this is probably related to homopolymerization 
inside the grafted films (that could not be extracted in water). Under these conditions, it was decided to perform grafting for 1 hour at $60{ }^{\circ} \mathrm{C}$ in the presence of $0.25 \mathrm{w} \%$ of Mohr's salt.

\subsection{Dose effect}

The irradiation dose also influences grafting reaction. When the absorbed dose increases, the number of excitation and ionization events increases as a consequence of the electronic interactions of the incident electrons with the polymer leading to an increase of the grafting initiators. If so, then increasing the number of radicals is expected to induce a continuous rise of the grafting yield. As shown in Figure 4 the grafting yield obtained in pure monomer passes through a maximum of approximately $14 \%$ at $10 \mathrm{kGy}$ and levels off just under $10 \%$ with further increasing dose. The influence of storage time as long as 5 years is also shown in Figure 4. It has no effect on the grafting yield at $10 \mathrm{kGy}$, but slightly decreases the grafting yield values for higher doses so that leveling off occurs more or less at ca $8 \%$.

In addition to the presence of a maximum grafting yield, differences are also observed in the behavior of the films dimensions. At $10 \mathrm{kGy}$ the grafted film expands and remains transparent while at higher doses, no expansion occurs and the films are opaque. As the absorbed dose increases, in most polymers part of primary radicals recombines leading to the formation of crosslinks. As the density of crosslinks increases, the polymer tends toward the formation of an insoluble network. The dose at which the film becomes insoluble (gel dose) can be estimated by sol-gel experiments in suitable solvents. The gel dose of PVDF is known to occur in the 20 to $30 \mathrm{kGy}$ range [33 and references therein]. Consecutively, at lower dose (10 kGy) PVDF polymer chains mobility allows a good accessibility of the monomer to bulk radicals thus increasing the grafting yield. The grafting occurs in the bulk; the PVDF film expands. At doses higher than the gel dose, only a fraction of primary radicals is reached by the monomer to start and propagate the grafting reaction because of the crosslinks induced by irradiation in the PVDF film. When the absorbed dose increases, the number of crosslinks 
increases which renders the penetration of the monomer progressively uneasy. Therefore, the grafting yield decreases and finally reaches a constant value in the dose-range examined. Similar behavior of the grafting yield with increasing dose was observed with vinyl fluoride (VF)/vinylidene fluoride copolymers electron grafted with NVP [34]. The copolymer with the lowest VF content (20 mol \%) shows a maximum close to $10 \mathrm{kGy}$ with a grafting yield of ca $20 \mathrm{w} \%$. It was assumed that the occurrence of the maximum was the point at which the grafting reaction became diffusion controlled: the monomer is consumed in the surface layers before it can reach the inside of the films.

\subsection{Grafting yield and monomer concentration dependence}

Figure 5 shows the variation of the grafting yield as a function of the AA concentration. It can be seen that by increasing monomer concentration, the grafting yield increases steadily up to approximately $40 \%$ at $50 \mathrm{v} \%$ of AA due to an increase of the polymerization rate. Then a rapid rise up to more than $120 \%$ at $80 \mathrm{v} \%$ of AA where the grafting yield is at a peak is observed. For higher AA concentrations (90 and $100 \mathrm{v} \%$ ), a sharp decrease of the grafting yield occurs.

The macroscopic examination of the grafted films show different results whether the monomer concentration is lower or higher than that of the peak at $80 \mathrm{v} \%$ of AA. For monomer concentrations below $80 \mathrm{v} \%$, the films were expanded and transparent. This was not the case for monomer concentrations higher than $80 \mathrm{v} \%$. The films did not exhibit any change of their surface area (very slightly for $90 \mathrm{v} \%$ ) and became white and non-transparent.

As is shown in Figure 6 which plots the surface area expansion $\left(\mathrm{Y}_{\mathrm{E}}=\frac{S f-S i}{S i} \cdot 100\right)$ as a function of the grafting yield, the surface area expansion is directly linked to the degree of swelling when the monomer concentration is below $80 \mathrm{v} \%$. It is linearly proportional to the grafting yield. For higher concentrations, the surface area expansion is close to zero. Also 
plotted in Figure 6 is the volume expansion $\left(\mathrm{Y}_{\mathrm{E}}=\frac{V f-V i}{V i} .100\right)$ versus the grafting yield. The volume expansion increases linearly with the grafting yield (correlation factor of 0.94 ) over the whole concentration-range. This illustrates that, at monomer concentrations higher than $80 \mathrm{v} \%$, all the PAA is grafted onto PVDF film surface and the thickness variation of the film gives directly the grafting yield.

Post-radiation grafting to polymeric films proceeds from the substrate surface, and as the films swell, the grafting progressively occurs throughout the films. This mechanism is known as the grafting front mechanism. It was first described in Chapiro's pioneer work in the early sixties [21]. Such a grafting front mechanism was evidenced in poly(vinyl fluoride) electron-grafted with $\mathrm{N}$-vinylpyrrolidone using differential interference contrast microscopy by Ellinghorst et al [35]. This mechanism depends on various parameters among which the solubility properties of monomer and graft polymer. Ellinghorst et al [36] also performed electron-grafting of PVDF with various monomers. In the case of AA, grafting-through could not be obtained in pure monomer at any temperature ranging from $50{ }^{\circ} \mathrm{C}$ to $80{ }^{\circ} \mathrm{C}$. As the PAA is insoluble in its monomer, the grafted PAA layer hinders the diffusion of AA molecules to the inner part of the film. The absorbed dose used by Ellinghorst et al was of 65 kGy which is about 3 fold less than the one used in this present work. Nevertheless, our results are consistent with theirs as we observe that grafting is localized on the PVDF surface in pure monomer where the mobility of the growing graft chains is substantially reduced by precipitation. Grafting with pure AA prevents the diffusion of monomer molecules to the inner part of the film due to its exclusion from graft PAA onto PVDF surface. Therefore, grafting occurs only at the surface creating a white PAA layer onto PVDF films surface. The addition of water molecules that solubilize both the PAA and the AA, allows the AA diffusion in the water soaked PAA top-layer. Water molecules act not only as a carrier for the monomer AA but also as a plasticizer of the soaked PVDF-g-PAA. Progressively, as the presence of 
water expands PVDF chain network and AA penetration into PVDF bulk is favored. This physical effect is predominant from 99 up to $80 \mathrm{v} \%$ of aqueous AA solution. At $80 \mathrm{v} \%$ of AA aqueous solution, an exact equimolarity exists between water molecules and AA units. Hydration is at its maximum. Radical sites induced by electron irradiation in the films bulk become all very accessible and PAA copolymerization can occur everywhere in the PVDF film, swelling it and expanding it in a homogeneous way. The isotropic PAA distribution in the PVDF matrix is attested by film transparency. Then, as more water molecules are added, the monomer concentration decrease reduces the polymerization rate and the grafting yield decreases, but grafting occurs in the bulk due to the plasticizing effects of the water molecules.

The grafting yield drops rapidly from $130 \mathrm{w} \%$ to $40 \mathrm{w} \%$, then slowly until $10 \mathrm{w} \%$. This is principally due to 2 additional effects that overcome the water plasticizing effect. Firstly, the dilution induces less monomer and less probability for AA to encounter another AA leading to a lower polymerization rate. Secondly, the increase in polymer chains mobility favors termination reactions on growing PAA chains.

At peak, despite the presence of the inhibitor in the solution, a contribution of the Trommsdorff effect to the dramatic increase of the grafting yield at $80 \mathrm{v} \%$ cannot be totally excluded. This gel effect is the result of a sudden self-acceleration of polymerization reaction enhanced by the decrease of the termination rate due to an increased polymerization medium viscosity.

\subsection{Morphology and structure of PVDF-g-PAA copolymers films}

To gain a better understanding of the grafting process, it is necessary to determine the graft distribution over the film thickness. Four different grafted films have been chosen: 2 transparent ones at 10 and $40 \mathrm{w} \%$ of grafting yield and 2 white films at 10 and $40 \mathrm{w} \%$ of grafting yield corresponding to initial monomer concentrations of 5, 50, 100 and $90 \mathrm{v} \%$ 
respectively. Films were immersed in a potassium tert-butoxide aqueous solution $(8: 8 \mathrm{w} / \mathrm{w})$ in order to deprotonate the PAA chains. Potassium PAA salts are obtained in $1 \mathrm{~h}$. After embedding in an epoxy resin, thin sections of the films were cut and observed perpendicular to the film surface by SEM coupled with X-ray detector. X-ray detection permits to obtain atomic distribution profiles across the film thickness by selecting potassium and fluorine $\mathrm{X}$ ray energies. Potassium reveals the AA distribution while fluorine, PVDF location.

Mechanical behavior is very different when comparing these 4 films. Highly grafted and expanded films are brittle while surface grafted ones (either highly or poorly grafted) remain as supple as the original PVDF. During microtoming, each one of them exhibited different cutting qualities (Figure 7) revealing various mechanical properties. The most brittle film corresponding to $[\mathrm{AA}] 50 \mathrm{v} \%$ is the most homogeneous. The other ones show stretches and rips depending on their grafting yield.

At low grafting yield in pure AA, potassium profile gives around $25 \%$ of graft on both edges and $50 \%$ of pure PVDF in the middle (Fig. 7a). It is clear that AA was not able to reach the inner part of PVDF film. At similar grafting yield but in presence of water ([AA]=5 w \%), the grafting front is more advanced due to water plasticizing effect as discussed in 3.4 (Fig. 7c). Indeed, only a thickness of $4 \mu \mathrm{m}$ is potassium free on [AA] $5 \mathrm{v} \%$ film compared to $10 \mu \mathrm{m}$ potassium free on [AA] $100 \mathrm{v} \%$ film. At higher grafting yield, grafting-through is achieved homogeneously in the bulk for $[\mathrm{AA}] 50 \mathrm{v} \%$ film (Fig. 7d). The penetration depth at similar grafting yield on [AA] $90 \mathrm{v} \%$ film is lower (Fig. 7b). At [AA] $90 \mathrm{v} \%$, [AA] has two fold molar excess compared to water molecules and the film is heterogeneous. EDAXS profiles confirm our assumption on the water plasticizing effect and its important role in the grafting-through process. It should be noted though, that fluorine atoms are detected throughout the entire analyzed film section giving indication of no real PAA layer, even on the "surface" grafted films. 
In order to get more data about surface chemical composition, XPS experiments were performed which give information on the top $\sim 5 \mathrm{~nm}$ polymer film. XPS survey spectra of virgin PVDF and PVDF-g-PAA samples are presented in Figure 8. The virgin PVDF shows a typical PVDF surface with an intense $F_{1 s}$ peak. The ratio of the $F_{1 s}$ to $C_{1 s}$ peaks is characteristic of the PVDF. After grafting, an additional peak of oxygen appears due to the presence of the grafted PAA. As illustrated (Figure 8) and calculated (Table 1), there is a significant decrease in relative $\mathrm{F}$ content going from grafting in presence of water ([AA] $5 \mathrm{v}$ $\%$ ) (Figure $8 \mathrm{c}$ ) to grafting without water ([AA] $100 \mathrm{v} \%$ ). In the latter case, no surface expansion is observed. Comparing these two samples, as the same surface area is analyzed, the decrease in the F content when pure AA is used for grafting is explained by coverage of the surface by the PAA chains. In the case of grafting in water, a small expansion of the surface occurs which lowers the F content, but much less than without water because the PAA chains are inserted between PVDF chains.

More detailed chemical analysis of PVDF surface modification is obtained from the $\mathrm{C}_{1 \mathrm{~s}}$ core level spectra depicted in Figure 9. Virgin PVDF $\mathrm{C}_{1 \mathrm{~s}}$ shows two peaks at $286.6 \mathrm{eV}$ and at $291.1 \mathrm{eV}$ for $\mathrm{CH}_{2}$ and $\mathrm{CF}_{2}$ respectively, separated by $4.5 \mathrm{eV}$. A slight oxidation of 3.2 $\%$ is detected due to oxidation during storage. The $\mathrm{O}_{1 \mathrm{~s}}$ corresponding signal was decomposed into two Gaussian peaks at $532.8 \mathrm{eV}$ and $534.6 \mathrm{eV}$ for $\mathrm{C}=\mathrm{O}$ and $\mathrm{C}-\mathrm{O}$ respectively (not shown). These oxidation defaults are mainly carboxylic acid type. After grafting, three additional peaks corresponding to PAA groups are observed at $285 \mathrm{eV}, 285.7 \mathrm{eV}$ and 289.4 $\mathrm{eV}$ for $\mathrm{CH}_{2}, \mathrm{CH}$ and $\mathrm{COOH}$ respectively. An oxidation peak at $287.3 \mathrm{eV}$ that represents near $5 \%$ of total $\mathrm{C}_{1 \mathrm{~S}}$ peaks area has to be added to the decomposition in order to fit properly the experimental data in accordance with the initial oxidation found on virgin PVDF (Table 1). The $\mathrm{O}_{1 \mathrm{~s}}$ core level spectrum also confirms oxidation presence by a $5 \%$ increase of $\mathrm{C}=\mathrm{O}$ 
component (spectrum not shown). This oxidation may come from initial PVDF film storage and post-irradiation oxidation.

When grafting in pure AA, the graft is mainly located in the surface as it was pointed out on SEM micrograph (Figure 7). Nevertheless, on XPS survey spectra (Figure 8), PVDF peaks are still present in the first $5 \mathrm{~nm}$ showing a partial PAA covering. The presence of PVDF indicates that a pure layer of PAA does not exist. The degree of covering was calculated from the $\mathrm{C}_{1 \mathrm{~s}}$ line as:

$$
\text { Covering Degree }(\%)=\frac{\frac{n_{P A A}}{3}}{\frac{n_{P V D F}}{2}+\frac{{ }^{n} P A A}{3}} .100
$$

where $n_{\text {PAA }}$ equals to PAA peaks area sum divided by Scofield factor and $n_{\text {PVDF }}$, PVDF peaks area sum divided by Scofield factor.

$\underline{\text { A covering degree of } 81 \% \text { was found for PVDF-g-PAA ([AA] } 100 \mathrm{v} \% \text { ) showing that }}$ even if no surface area expansion is detected, the top surface layer is composed of substrate and grafted macromolecular chains.

In presence of water, at a fixed grafting yield, the PAA covering degree was equal to $57 \%$ for PVDF-g-PAA ([AA] $5 \mathrm{v} \%$ ). The higher PVDF peaks contribution (Figure 9) together with surface area expansion give evidence of grafting-through process of increased diffusion of AA in the PVDF.

The PAA layer should then be rather represented by a PAA gradient from the PVDF film surface to the inner part with various penetration front location and densities depending on initial grafting conditions.

\subsection{PAA quantification}

The chemical composition of PVDF-g-PAA copolymers films was determined by FTIR in transmission and ATR mode. Transmission spectra give information on the bulk of 
the films while the ATR experiments analyze roughly the first micrometer of the films at 2000 $\mathrm{cm}^{-1}$. All spectra of the PVDF-g-PAA films were similar and previously described in detail [12]. A characteristic band for the $\mathrm{O}-\mathrm{C}=\mathrm{O}$ stretching $\left(v=1710 \mathrm{~cm}^{-1}\right)$ related to the $\mathrm{COOH}$ groups of the grafted PAA chains (Figures 10, 11 and 12) is observed. The corresponding $\mathrm{OH}$ vibration gives rise to a broad band in the $2500-3500 \mathrm{~cm}^{-1}$ region on which are superimposed the $\mathrm{CH}_{2}$ asymmetric and symmetric stretching absorption bands of PVDF at $3025 \mathrm{~cm}^{-1}$ and $2985 \mathrm{~cm}^{-1}$, respectively. The $1500-400 \mathrm{~cm}^{-1}$ range gives no useful information in transmission because of the high intensity absorption bands of PVDF. Since the concentration of a functional group is directly proportional to its absorption peak area, the absorption intensity of every absorption band related to PAA increases as the grafting yield increases (Figure 10). The PAA carbonyl absorption band of very high intensity due to a high absorption coefficient is close to the saturation even at ca $10 \%$ grafting yield.

Figures 11 and 12 were obtained in ATR mode and compare the surface of grafted samples with different structure for two comparable grafting yields. Contrarily to transmission mode, ATR analysis investigates the first $0.55 \mu \mathrm{m}$ of the film surface at $3000 \mathrm{~cm}^{-1}$. In ATR mode, surface grafted films spectra ([AA] of 90 and $100 \mathrm{v} \%$ ) have stronger absorption intensity for PAA signals than bulk grafted films. Conversely, the $\mathrm{CH}_{2}$ PVDF stretching vibration doublet remains observable for bulk grafted PVDF-g-PAA films and almost completely disappears for surface grafted PVDF-g-PAA films. This is in agreement with XPS results where a higher density of PAA is observed in the surface in the case of "surface" grafted film.

An unexpected peak at $1555 \mathrm{~cm}^{-1}$ was also observed. It was more or less expressed from a sample to another. By immersing films into an acidic $\mathrm{H}_{2} \mathrm{SO}_{4}$ solution ( $\mathrm{pH}$ 2) at different times, it was demonstrated that the decrease of this peak contributes to the increase of the $\mathrm{COOH}$ peak at $1710 \mathrm{~cm}^{-1}$ (figure 13). This suggests that the peak at $1555 \mathrm{~cm}^{-1}$ corresponds to 
carboxylates (asymmetric stretching vibration of $\mathrm{CO}_{2}^{-}$) that progressively converse in acids upon acidification of the films. This conversion is reversible though the films loose mechanical properties progressively.

Quantification of carboxylic functions by IR was therefore difficult due to different molar absorption coefficient of carboxyl functions. Therefore quantification was performed using analytical methods. Firstly pH-titration was achieved. PVDF-g-PAA films were immersed in a titrated sodium hydroxide solution for one hour. Aliquots of this solution were then titrated by hydrochloric acid. This back-titration permits to dose accurately millimoles of AA. The accuracy requires controlled conditions such as the use of boiled deionized water to avoid undesired carbonatation, titrated solutions (Titrisol®) and automatic burette. For low yield grafted films, this technique was inadequate and a UV-visible back-titration was necessary to dose the micromole of AA. Quantification using toluidine blue (TB) was adapted from Kang et al [19]. For "surface" grafted films with roughly $7 \%$ grafting yield ([AA] $=100$ $\mathrm{v} \%$ ), molar TB/AA ratios are very low and equal to $0.066 \pm 0.017$ corresponding to $0.15 \pm$ $0.07 \mu \mathrm{mol} / \mathrm{cm}^{2}$. With higher "bulk" grafted films obtained with $[\mathrm{AA}]=50 \mathrm{v} \%$ (ca $\left.27 \%\right)$, molar TB/AA ratio decreases to $0.020 \pm 0.009$. However, as the surface area is expanded in this latter case the toluidine blue molar number per area unit equal to $0.12 \pm 0.09 \mu \mathrm{mol} / \mathrm{cm}^{2}$ remains unchanged. This means that toluidine blue doses only AA units present on the uppermost surface. Thus, this value corresponds to the saturation limit. Steric hindrance avoids toluidine blue to access to all AA units.

Cupric ions are smaller and have a high affinity for EDTA (ethylene diamine tetra-acetic acid). A protocol was then elaborated to back-titrate low yield grafted films immersed in a cupric ion solution and desorbed in EDTA solution. The EDTA-cupric ion complexes are dosed by UV-visible spectroscopy. Two salts have been tested: Copper II sulphate and Copper II chloride. With Copper II sulphate $100 \%$ of AA units are accurately 
dosed with a $\mathrm{Cu}^{2+} / \mathrm{AA}$ molar ratio equal to $1.02 \pm 0.13$ while with copper II chloride only 75 $\%$ of the AA units are dosed with a $\mathrm{Cu}^{2+} / \mathrm{AA}$ molar ratio equal to $0.74 \pm 0.11$. This is due to the difference of $\mathrm{pH}$ between the two solutions, for the used conditions, $\mathrm{pH}_{\mathrm{CuSO} 4}$ is greater than $\mathrm{pH}_{\mathrm{CuCl} 2}$. A small fraction of the pendant acid groups along the PAA chain is ionized in contact with $\mathrm{CuCl}_{2}$ solution. The difference of reactivity which is less for carboxylates than for carboxylic acid explains the observed difference.

\section{CONCLUSION}

Several parameters governing the structure and morphology of PVDF-g-PAA films have been determined. Initial grafting conditions are important for the final mechanical properties of the materials. Grafting-through or "surface" grafting processes can be achieved by varying the water fraction in the initial monomer solution. Evidence of the plasticizing effect of water molecules was pointed out and confirmed by SEM coupled to X-ray analysis. For "surface" grafting, a highly dense PAA layer covers PVDF films surface. As far as it is dense, it is not a pure PAA layer as grafted chains are intimately mixed with PVDF chains. When adding water, the PAA density becomes less important and the grafting through process occurs more easily. The two grafting fronts diffuse with increasing grafting yield from both surfaces to the inner part of PVDF film until they join to obtain a complete homogeneous PVDF-g-PAA copolymer film.

The development of accurate back-titration technique was performed to quantify the micromole of AA trapped in PVDF bulk using UV-visible spectroscopy. They reveal that the accessibility of AA carboxylic functions depends greatly on the molecular size of the probes. Therefore, the choice of the dosing method can be chosen depending on the functionalization goals. Also, biology and interface chemistry would certainly push us to displace the detection limits to nanomole determination. In this purpose, we are planning to adapt biochemistry dosing techniques. 
The possibility to design the grafted film structure can be of interest for various application fields such as membranes where grafting-through is required or biomaterials where often the surface properties need to be different than that of the bulk.

\section{ACKNOWLEDGEMENTS}

This work was performed in the frame of the LRC DSM 98-15. The authors gratefully acknowledge the financial support by a grant from Lefoulon-Delalande Foundation (Institut de France, Paris). 


\section{REFERENCES}

1. Ying L, Wang P, Kang ET, Neoh KG. Macromolecules 2002;35:673-679.

2. Pasquier AD, Warren PC, Culver D, Gozdz AS, Amatucci GG. Solid State Ionics 2000;135:249.

3. Tarvainen T, Svarfvar B, Akerman S, Savolainen J, Karhu M, Paronen P, Järvinen K. Biomaterials 1999;20:2177-2183.

4. Jarvinen K, Akerman S, Svarfvar B, Tarvainen T, Viinkka P, Paronen P. Pharmaceutical Research 1998;15(5):802-805

5. Suh TS, Joo CK, Kim YC, Lee MS, Lee HK, Choe BY, Chun HJ. J. Appl. Polym. Sci. 2002;85(11):2361 2366.

6. Gancarz I, Pozniak G, Bryjak M, Frankiewicz A. Acta Polym. 1999;50:317-326.

7. Dogué IL, Mermilliod N, Foerch R. Nucl. Instr. and Meth. B 1995;105(1-4):164-167.

8. Lei J, Liao X. Eur. Polym. J. 2001;37:771-779.

9. El-Sawy NM, Al Sagheer FA. Polym. International 1998;47:324-330.

10. Mokhtar SM. Polym. International 1997;42:335-339.

11. Aouadj S, Chapiro A. Die Angew. Makromol. Chem. 1996;235:73-80.

12. Betz N, Bègue J, Goncalves M, Gionnet K, Déléris G, Le Moël A. Nucl. Instr. and Meth. B 2003;208:434441.

13. Zouahri A, Elmidaoui A. J. of Polym. Sci., Part A : Polymer Chemistry 1996;34:1793-1798.

14. Tamura N, Shinohara K. Prept. Prog. Polym. Phys. Japan 1963;6:265.

15. Helbert JN, Wagner BE, Pointdexter EH, Kevan L. J. Polym. Sci., Polym. Phys. Edn. 1975;13:825.

16. Suryanarayana D, Kevan L. J. Am. Chem. Soc. 1982;104:6251.

17. Betz N, Petersohn E, Le Moël A. Radiat. Phys. Chem. 1996;47:411-414.

18. Steffens G, Nothdurft L, Buse G. Biomaterials 2002;23(16):3523-3531.

19. Kang ET, Tan KL. Macromolecules 1996;29:6872-6879.

20. Scofield JH. J. Electron Spectrosc. Relat. Phenom. 1976;8:129.

21. Chapiro A. Radiation Chemistry of Polymeric Systems. In: Mark H, Marwell CS, Melville HW editors.

High Polymers, vol. XV. New York: Interscience, 1962.

22. Chapiro A. J. Polym. Sci. : Symp. 1975;50:181-188.

23. Rånby B, Rabek JF. Esr Spectroscopy in Polymer Research. Polymers/Properties and Applications 1, vol. Berlin: Springer-Verlag, 1977.

24. Bozzi A, Chapiro A. Eur. Polym. J. 1987;23:255-257.

25. Dmitrenko AV, Serushkin MI, Mesh AM, Agnivtseva TG, Ivanchev SS. Polym. Sci. USSR 1992;34(4):319323.

26. Aymes-Chodur C, Ph D, University Pierre et Marie Curie, Paris, France.

27. Guilmeau I, Esnouf S, Betz N, Le Moël A. Nucl. Instr. and Meth. B 1997;131:270-275.

28. Le Bouëdec A, Ph. D. Thesis, University of Caen, France, Caen.

29. Niemöller A, Ellinghorst G. Die Angew. Makromol. Chem. 1987;148:1-18.

30. Guilmeau I, Ph; D. Thesis, University Pierre et Marie Curie (Paris VI), Paris.

31. Betz N, Moël AL, Balanzat E, Ramillon JM, Lamotte J, Gallas JP, Jaskierowicz G. J. Polym. Sci. : part B, Polym. Phys. 1994;32:1493-1502.

32. Boullier I, Esnouf S, Moël AL. Journal of Polymer Science B: Polymer Physics 2003;41:1509-1517.

33. Betz N, Petersohn E, Le Moël A. Nucl. Instr. and Meth. B 1996;116:207-211.

34. Vierkotten D, Ellinghorst G. Die Angew. Makromol. Chem. 1983;113:153-168.

35. Ellinghorst G, Fuehrer J, Vierkotten D. Radiat. Phys. Chem. 1981;18(5-6):889.

36. Ellinghorst G, Niemöller A, Vierkotten D. Radiat. Phys. Chem. 1983;22(3/5):635-642. 


\section{TABLES}

\section{Table 1}

Atomic percentage of $\mathrm{C}, \mathrm{O}, \mathrm{F}$ and $\mathrm{Si}$ from XPS for virgin PVDF, "surface" grafted PVDF-g-PAA ([AA] $100 \mathrm{v} \%$ ) and grafted through PVDF-g-PAA ([AA] 5 v \%). (Survey spectra are shown of Fig. 8, values were obtained from core line spectra of Fig. 9)

\begin{tabular}{llll}
\hline Surface & $\mathrm{C}_{1 \mathrm{~S}}(\%)$ & $\mathrm{O}_{1 \mathrm{~S}}(\%)$ & $\mathrm{F}_{1 \mathrm{~S}}(\%)$ \\
\hline Virgin & 49.3 & 3.2 & 47.5 \\
"Surface" grafting & $\underline{61.4}$ & $\underline{37.7}$ & 0.4 \\
Grafting through & 70.5 & 15.4 & 12.2 \\
\hline
\end{tabular}

\section{FIGURE CAPTIONS}

Figure 1 FTIR transmission PVDF spectra illustrating the effect of a $150 \mathrm{kGy}$ electron irradiation (a, a') and $24 \mathrm{~h}$ annealing at $60{ }^{\circ} \mathrm{C}$ under $\mathrm{N}_{2}\left(\mathrm{~b}, \mathrm{~b}^{\prime}\right)$ atmosphere.

Figure 2 Grafting yield versus Mohr's salt concentration, [AA] $=75 \mathrm{v} \%, 150 \mathrm{kGy}, 60{ }^{\circ} \mathrm{C}$, $1 \mathrm{~h}$.

Figure 3 Grafting kinetics: $(\boldsymbol{\nabla}) 100 \mathrm{kGy} ;(\bullet) 30 \mathrm{kGy},[\mathrm{AA}]=100 \mathrm{v} \%$, [Mohr's salt $]=$ $0.25 \mathrm{w} \%, 60{ }^{\circ} \mathrm{C}$.

Figure 4 Grafting yield versus absorbed dose, $[\mathrm{AA}]=100 \mathrm{v} \%$, [Mohr's Salt $]=0.25 \mathrm{w} \%$, $60{ }^{\circ} \mathrm{C}, 1 \mathrm{~h}$.

Figure 5 Grafting yield versus monomer concentration, $150 \mathrm{kGy}$, [AA] $=100$ v \%, [Mohr's Salt $]=0.25 \mathrm{w} \%, 60{ }^{\circ} \mathrm{C}, 1 \mathrm{~h}$.

Figure 6 Film expansion versus grafting yield, $\circ$ volume, $\diamond$ surface; $\diamond$ surface expansion of "surface" grafting samples; $150 \mathrm{kGy},[\mathrm{AA}]=100 \mathrm{v} \%$, [Mohr's Salt $]=0.25 \mathrm{w} \%, 60{ }^{\circ} \mathrm{C}, 1 \mathrm{~h}$. 
Figure 7 SEM micrographs and profiles of PVDF-g-PAA films initially irradiated at 150 $\mathrm{kGy}$, grafted at $60{ }^{\circ} \mathrm{C}, 1 \mathrm{~h}$ with [Mohr's Salt] $=0.25 \mathrm{w} \%$ and treated in a solution of tBuOK $(8: 8 \mathrm{w} / \mathrm{w})$. (a) $\mathrm{Y}=8.8 \mathrm{w} \%,[\mathrm{AA}]=5 \mathrm{v} \%$, (b) $\mathrm{Y}=40.8 \mathrm{w} \%,[\mathrm{AA}]=50 \mathrm{v} \%$, (c) $\mathrm{Y}=11.3 \mathrm{w}$ $\%,[\mathrm{AA}]=100 \mathrm{v} \%$; (d) $\mathrm{Y}=47.21 \mathrm{w} \%,[\mathrm{AA}]=90 \mathrm{v} \%$. In profiles, red corresponds to potassium and blue, to fluorine atoms.

Figure 8 XPS survey spectra of (a) virgin PVDF, (b) PVDF-g-PAA, [AA] $=100$ v \%, Y = 13 $\%$, (c) PVDF-g-PAA, [AA] $=5 \mathrm{v} \%, \mathrm{Y}=13 \%$.

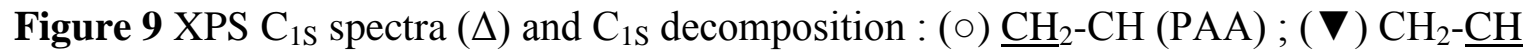

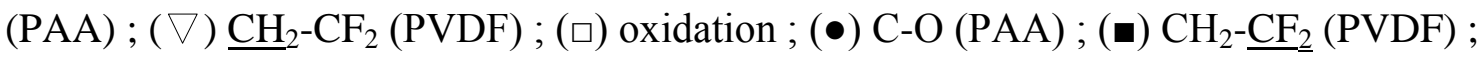
base line ; - fit

Figure 10 FTIR transmission spectra of 150 kGy electron irradiated PVDF and PVDF-g-PAA films copolymers at $10 \%$ grafting yield, $[\mathrm{AA}]=100 \mathrm{v} \%$ and $40 \%$ grafting yield, $[\mathrm{AA}]=50$ v \% -[Mohr’s Salt $]=0.25 \mathrm{w} \%, 60{ }^{\circ} \mathrm{C}, 1 \mathrm{~h}$.

Figure 11 FTIR spectra in ATR mode - Comparison between PVDF-g-PAA synthesized from $[\mathrm{AA}]=50 \mathrm{v} \%$ and $[\mathrm{AA}]=90 \mathrm{v} \%-150 \mathrm{kGy},[$ Mohr's Salt $]=0.25 \mathrm{w} \%, 60{ }^{\circ} \mathrm{C}, 1 \mathrm{~h}$.

Figure 12 FTIR spectra in ATR mode - Comparison between PVDF-g-PAA synthesized from $[\mathrm{AA}]=5 \mathrm{v} \%$ and $[\mathrm{AA}]=100 \mathrm{v} \%-150 \mathrm{kGy},[$ Mohr's Salt $]=0.25 \mathrm{w} \%, 60{ }^{\circ} \mathrm{C}, 1 \mathrm{~h}$.

Figure 13 Carboxyl peaks height of $30 \%$ bulk grafted PVDF-g-PAA film versus time in aqueous solution of $\mathrm{H}_{2} \mathrm{SO}_{4}(\mathrm{pH} 1):(\bullet) 1555 \mathrm{~cm}^{-1}$; ( $) 1710 \mathrm{~cm}^{-1}$; (•) sum of heights -150 $\mathrm{kGy},[\mathrm{AA}]=25 \mathrm{v} \%$, [Mohr's Salt $]=0.25 \mathrm{w} \%, 60^{\circ} \mathrm{C}, 1 \mathrm{~h}$. 
Figure 1
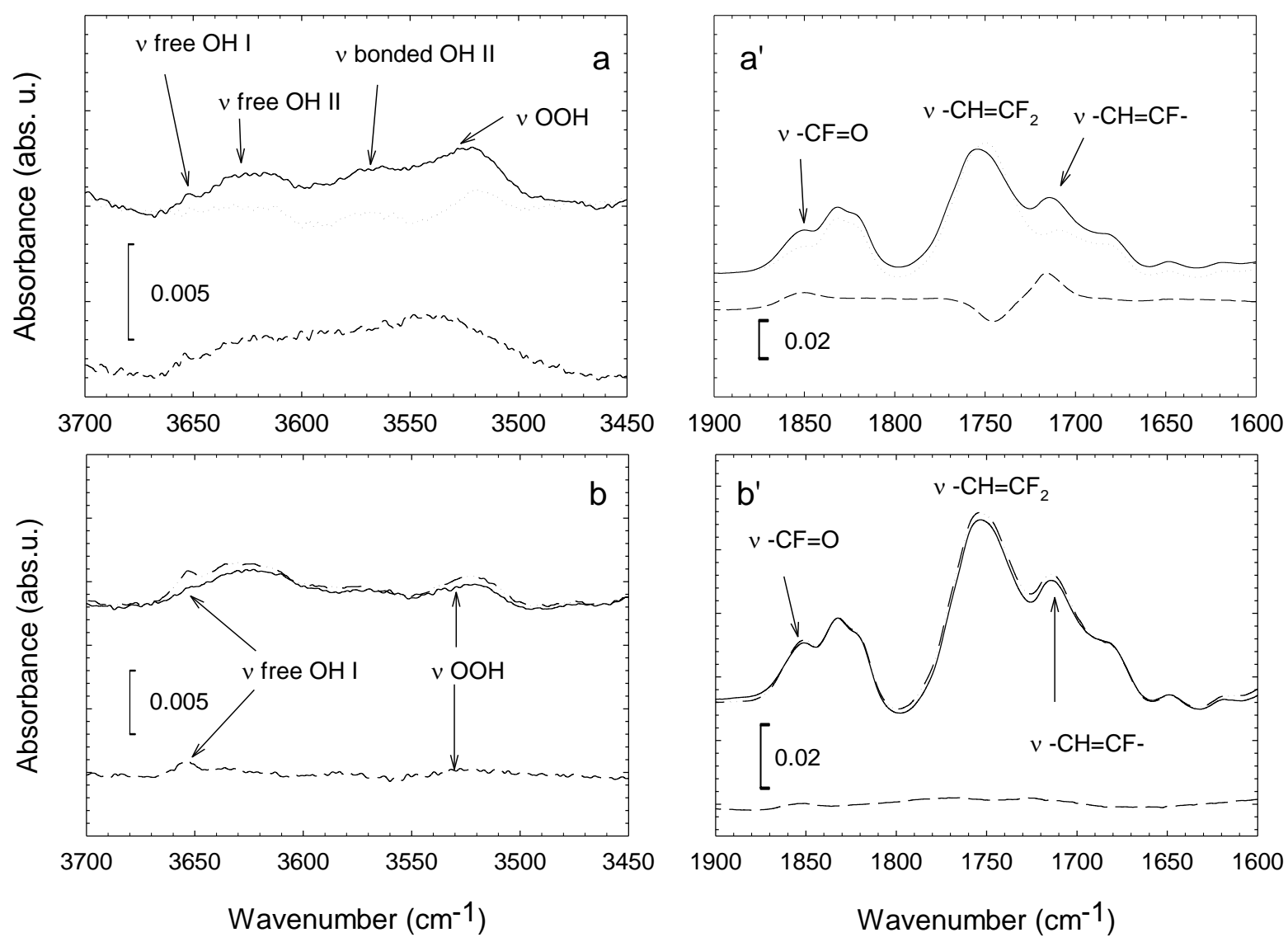

\begin{tabular}{|c|c|}
\hline Virgin PVDF & Irradiated PVDF \\
\hline Annealed PVDF & _ _ - Substraction \\
\hline
\end{tabular}


Figure 2

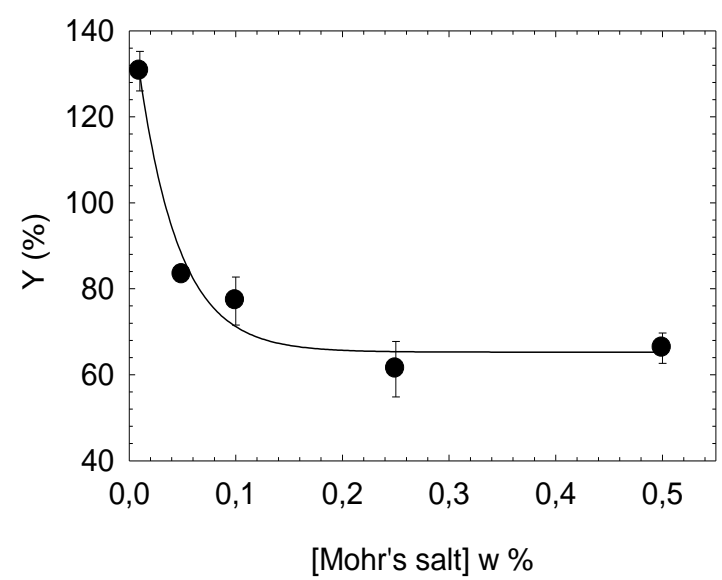

Figure 3

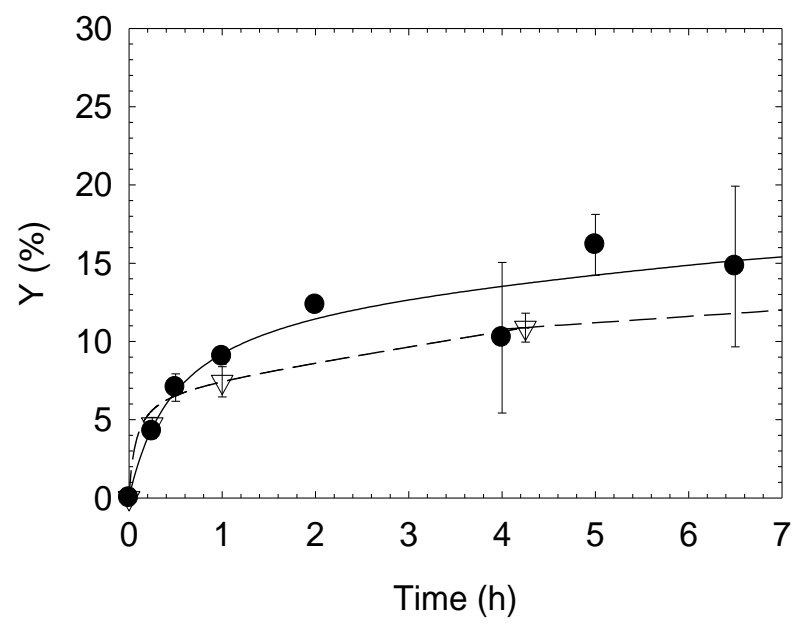

Figure 4

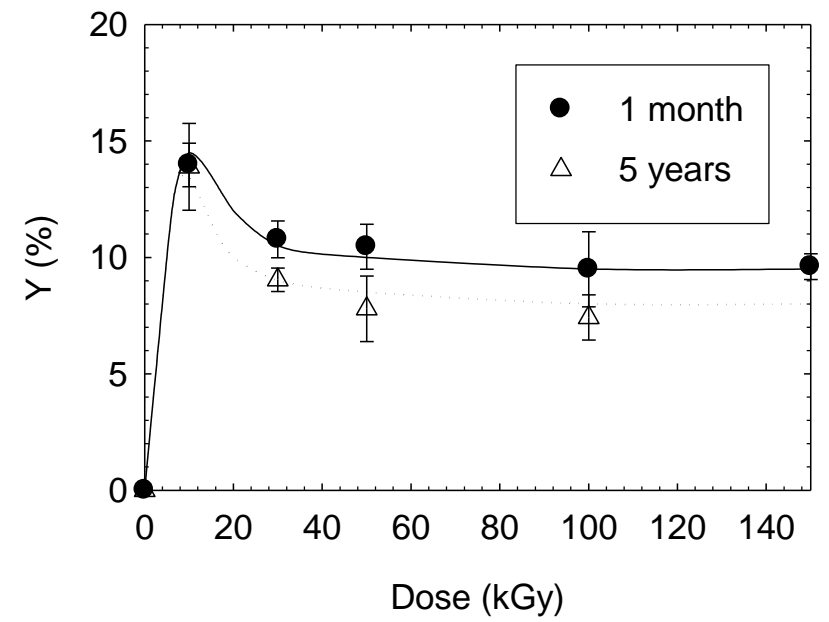


Figure 5

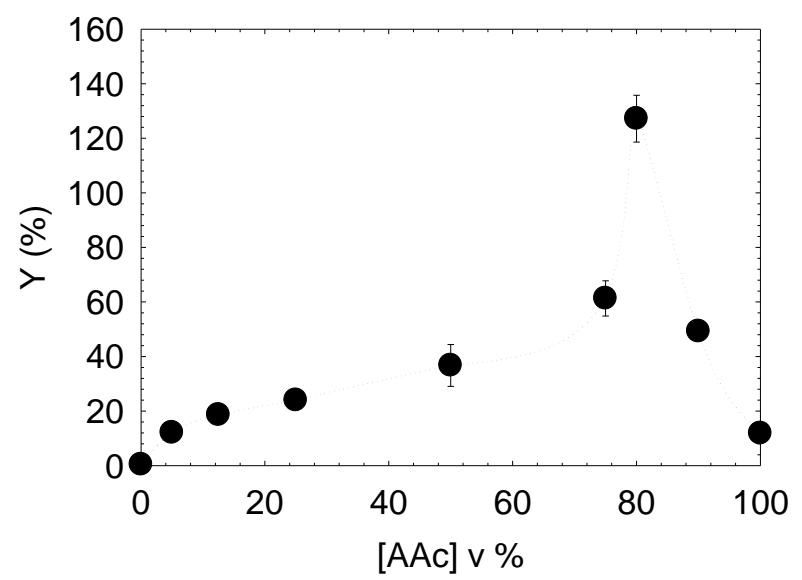

Figure 6

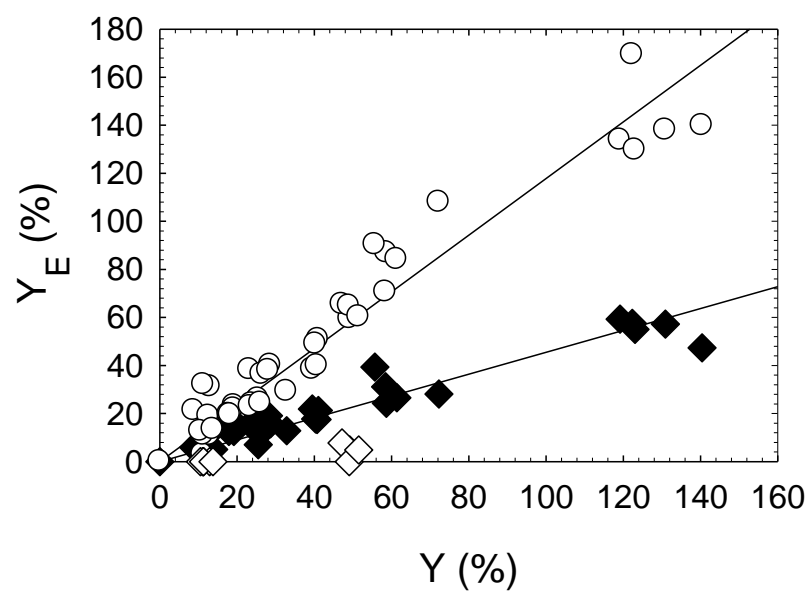


Figure 7

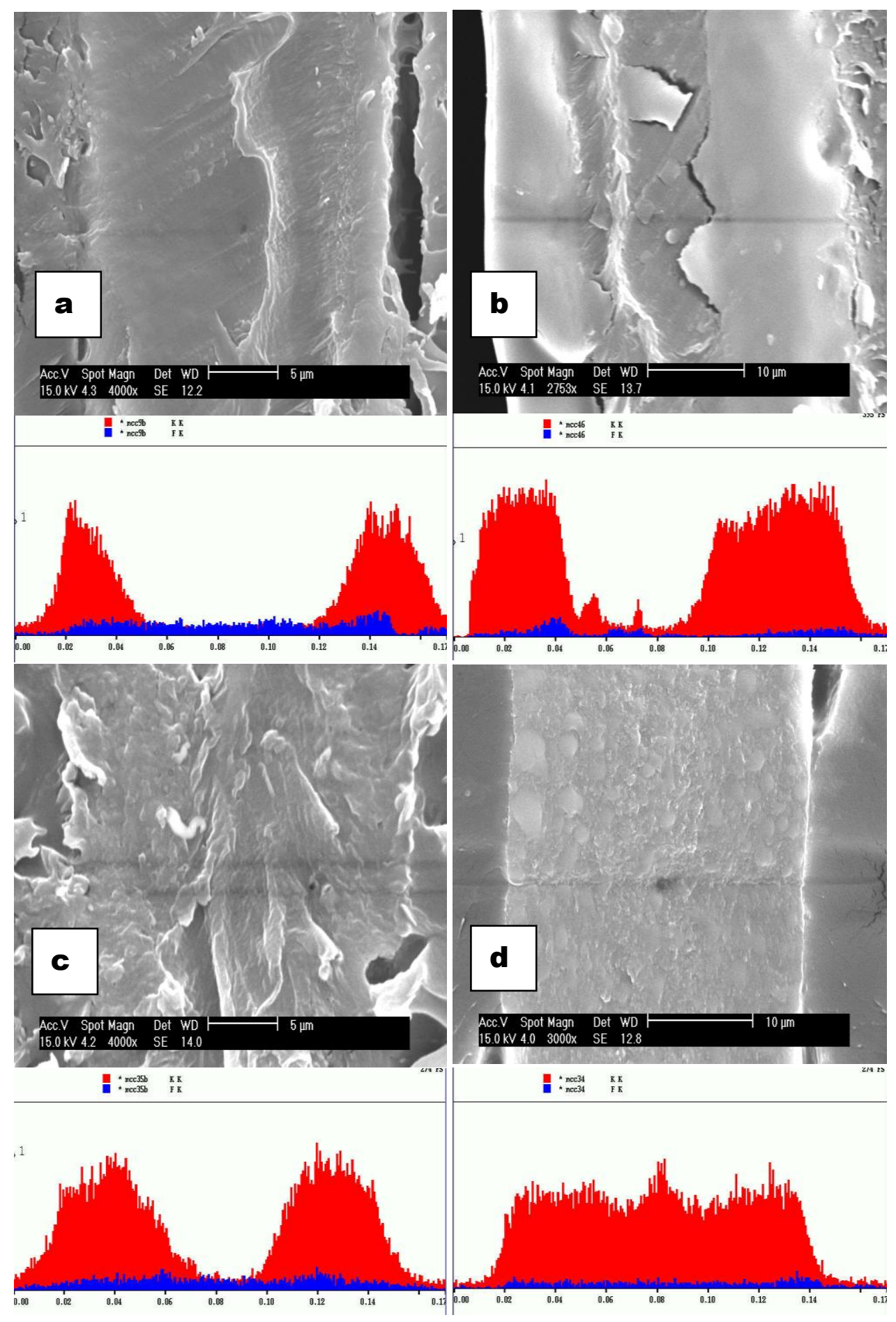



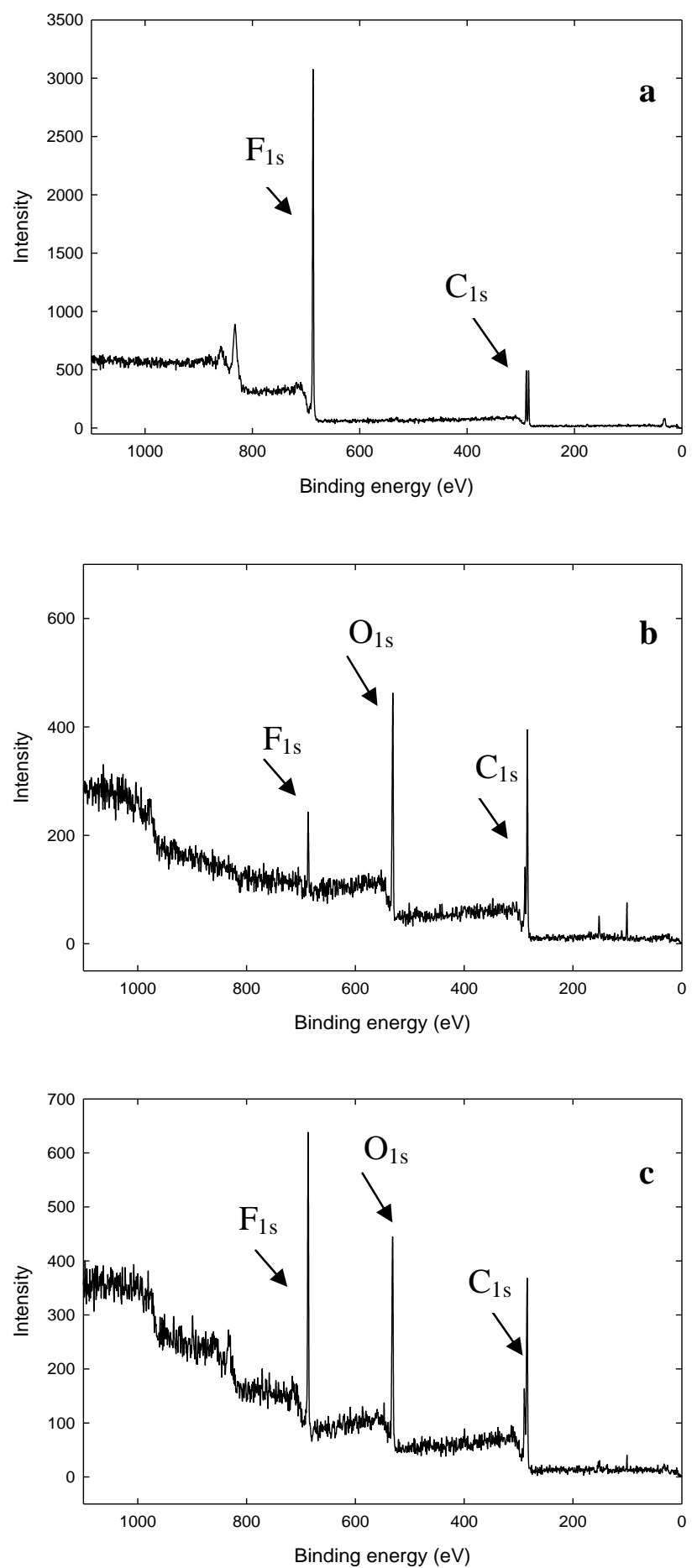

Figure 8 

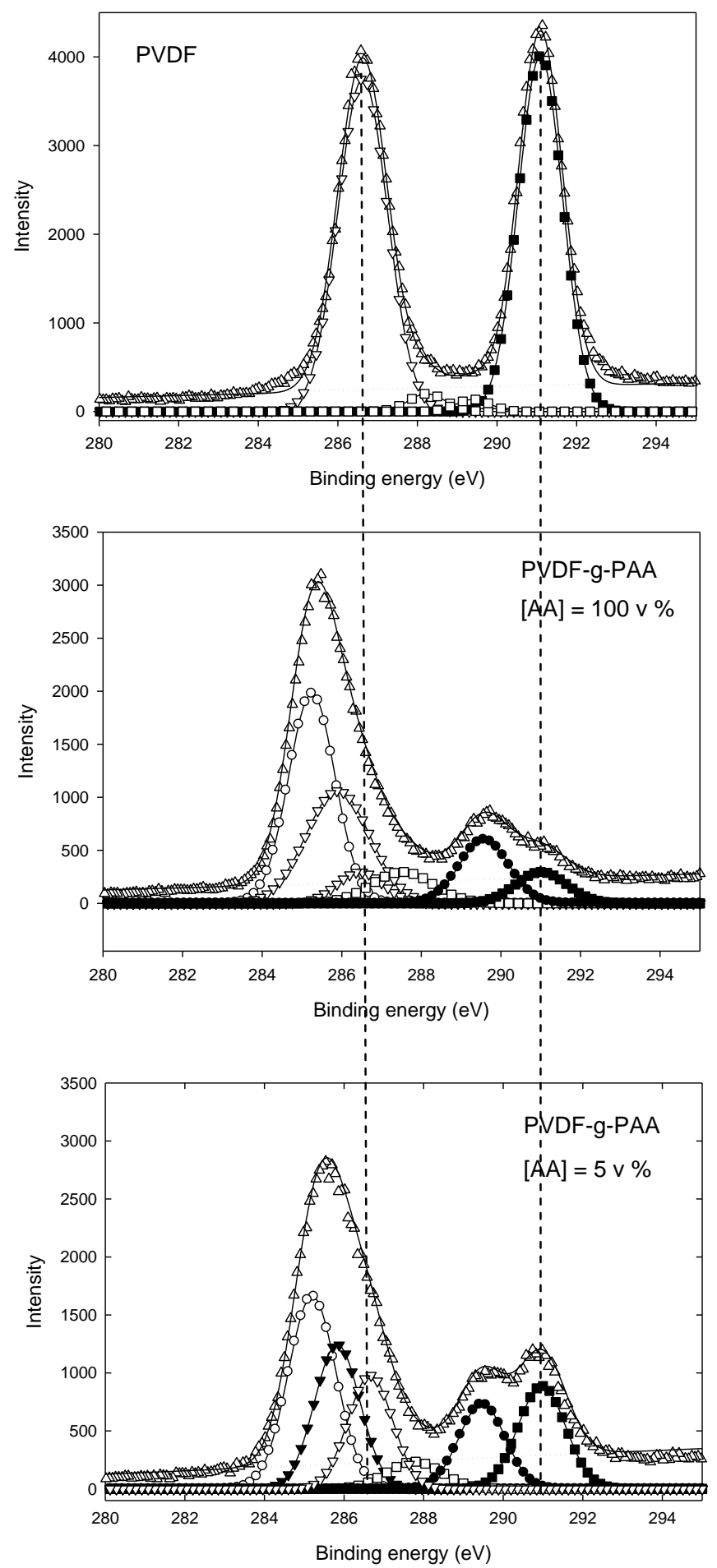

Figure 9 
Figure 10

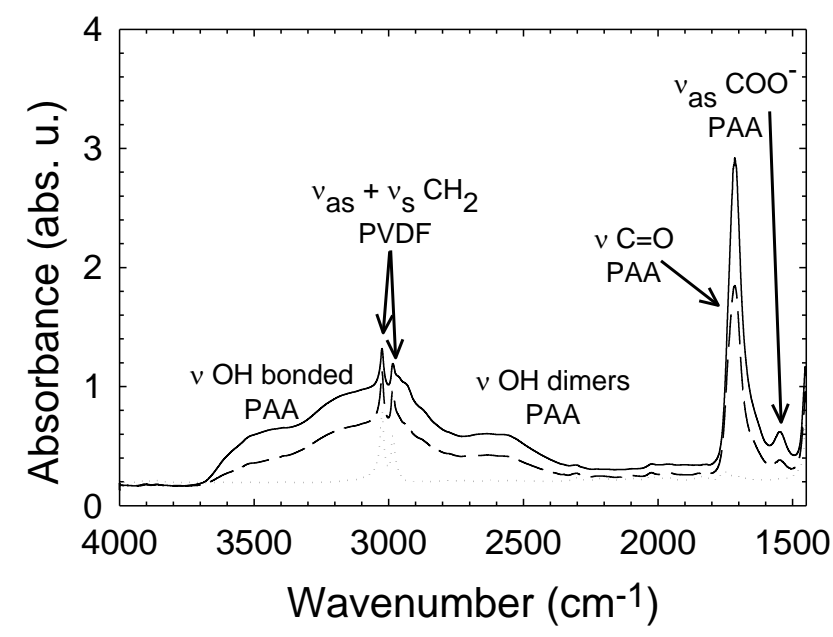

Figure 11
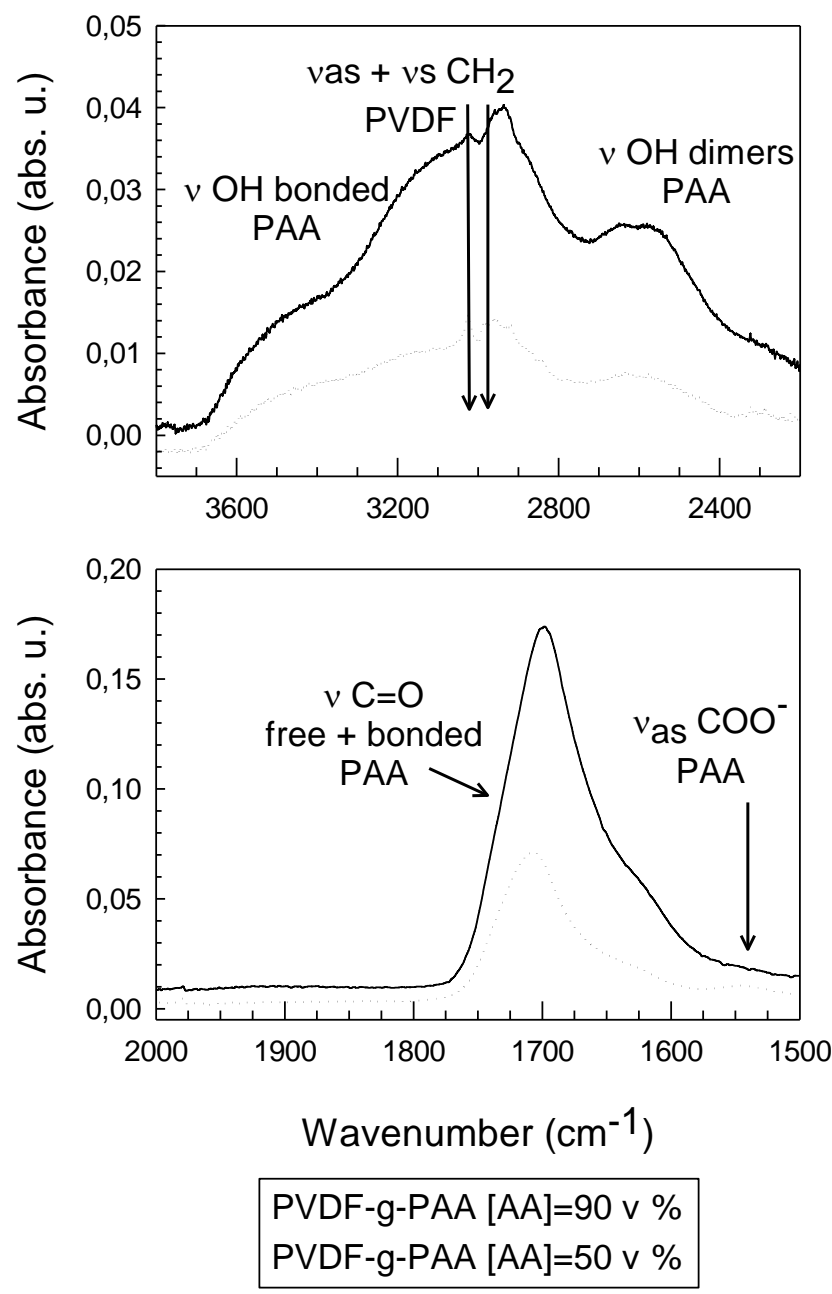
Figure 12
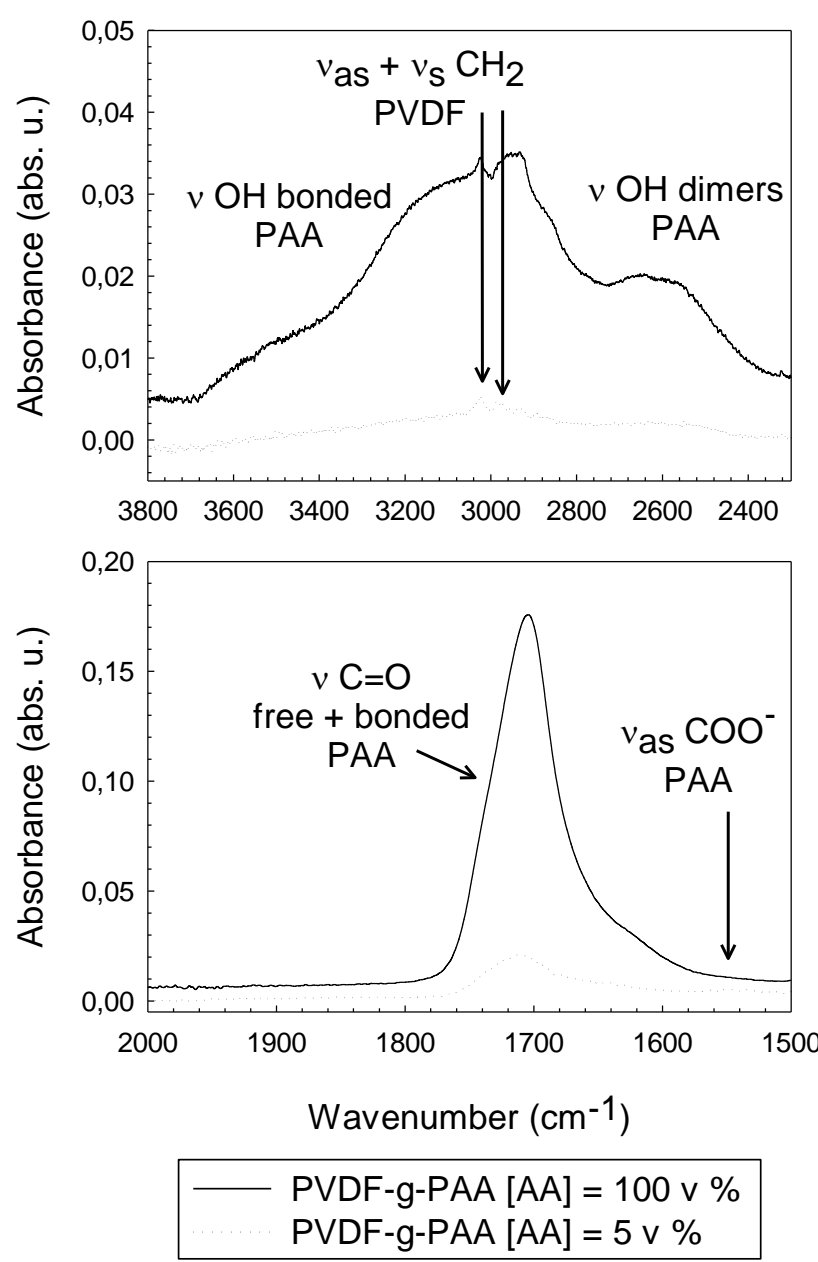

Figure 13

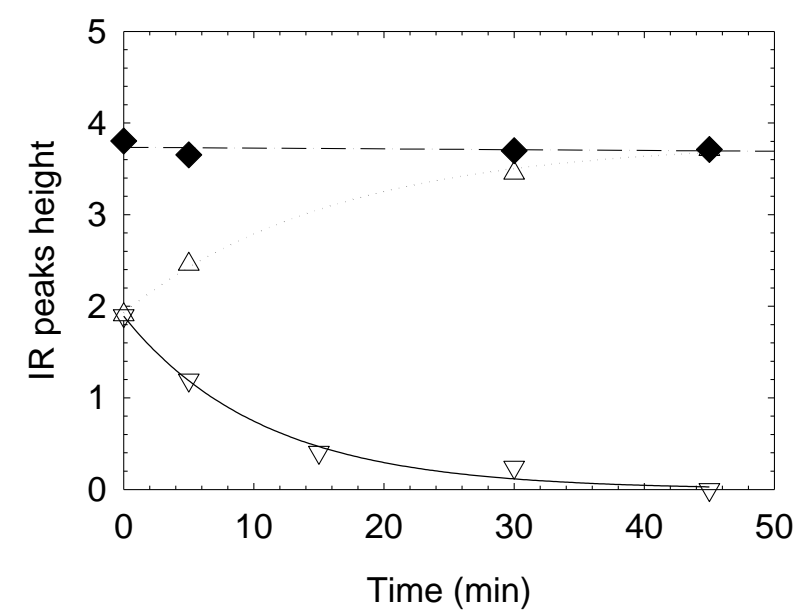

